\title{
Baltic Sea Regional Advisory Council as a hybrid management framework for sustainable fisheries
}

\author{
R. Aps ${ }^{1}$, M. Fetissov ${ }^{1}$, L. Kell ${ }^{2} \&$ H. Lassen ${ }^{3}$ \\ ${ }^{1}$ Estonian Marine Institute, University of Tartu, Estonia \\ ${ }^{2}$ Centre for Environment, Fisheries \& Aquaculture Science (Cefas), UK \\ ${ }^{3}$ International Council for the Exploration of the Sea (ICES), Denmark
}

\begin{abstract}
The Baltic Sea Regional Advisory Council (BS RAC) was set up in March 2006 with the aim of contributing to sustainable use of the Baltic Sea fishery resources under the EU Common Fisheries Policy. The BS RAC can be seen as an international boundary organization mixing scientific and political elements, and mediating between the institutions of science and politics. This paper attempts to explore the performance of the BS RAC as a boundary organization in producing recommendations to the EU Commission. Bayesian Belief Network (BBN) methodology is used to identify the uncertainty reducing capacity of the evidence - information on argumentation strength available in the course of the advisory consultations.
\end{abstract}

Keywords: Baltic Sea Regional Advisory Council, hybrid management, boundary organizations, decision overfishing.

\section{Introduction}

The Baltic Sea Regional Advisory Council (BS RAC) was set up in March 2006 with the aim of contributing to the sustainable use of the Baltic Sea fishery resources under the EU Common Fisheries Policy. The BS RAC can be seen as an international boundary organization, mixing scientific and political elements, and mediating between the science institutions, fisheries' associations, producer organisations, processors, market organisations, environmental NGOs, 
aquaculture producers, consumers, women's networks and recreational and sports fishermen, and the institutions of politics.

BS RAC is considered as a hybrid in the sense of the theory of hybrid management as developed by Miller [1]. He defines hybrids as social constructs that contain both scientific and political elements, often sufficiently intertwined to render separation a practical impossibility. Hybrid management focuses on the functions of organizations engaged in co-production, including such functions as hybridization, deconstruction, boundary work and cross-domain co-ordination. According to Guston [2], boundary organizations deal with social arrangements, networks and institutions that mediate between the institutions of science and of politics. Boundary organizations are an increasingly common phoneme. To maintain productive and dynamic relationships, boundary organizations need to be able to manage hybrids - to put scientific and political elements together, take them apart, establish and maintain boundaries between different forms of life, and coordinate activities taking place in multiple domains [1]. Furthermore, by helping to manage hybrids, boundary organizations contribute to the maintenance of a productive tension between science and politics. Boundary organizations appear to need the approval of science for the credibility of their knowledge claims as well as the approval of political institutions for the legitimacy of their policy orientations.

In European seas, overfishing continues to be a major problem, largely because the forces driving overexploitation have not been properly addressed [3]. Regulatory overfishing is referring to potential political and social causes in regulated fisheries, and to how political and social forces actually manifest themselves in fisheries management [4]. Overcapacity (a fleet's excess catch capacity relative to the level of catch that would allow the resource to be sustainably exploited) is considered to be one of the factors of overfishing. The persisting problem of fleet overcapacity was considered as an important negotiation context element when setting the Total Allowable Catches (TACs) for the internationally regulated Baltic fish stocks [5].

This paper attempts to explore the performance of the BS RAC as a boundary organization producing recommendations to the EU Commission on fisheries issues under the Common Fisheries Policy (CFP). Bayesian Belief Network (BBN) methodology is used to identify the uncertainty reducing capacity through investigating the argumentation strength available in a course of the advisory negotiations.

In this analysis we use argumentation analysis to predict among the possible decisions which will actually be decided upon rather than just assessing the probability that a particular decision will be made. In particular, it should be possible to assess the potential reasons (i.e. arguments) why a decision is made, and to combine and compare arguments in order to understand the balance of interests behind the decision [5]. The BS RAC advice could be seen as the hybridization of at least three different settings: 1) ICES science based advice, 2) non-industry stakeholder's argumentation, and 3) industry stakeholder's argumentation. 


\section{Material and methods}

Conceptual model of the BS RAC consultation process is developed using the BBN methodology and the HUGIN RESEARCHER software. Hypotheses generation representing the BS RAC advice options on setting the Total Allowable Catches (TACs) as well as setting the conditional probabilities have been done externally based on the BS RAC Statements and Recommendations for 2007-2008 [6], and International Council for the Exploration of the Sea (ICES) Advice on the Baltic fish stocks [7]. BBNs are the modelling tools that facilitate the development of formal representations of a problem or question. Most often these are cast in numerical terms but may also deal with qualitative variables. The great advantage of BBN modelling is that it compels users to clearly articulate variables and the relationships among variables. BBNs are based on the Bayesian formalism, the centre piece of which is the Bayes' rule, which allows a decision maker to update his subjective belief when new facts are uncovered.

Bayesian decision theory and value of information analysis provides an analytical framework that is used to establish the value of acquiring additional information to inform a decision problem. Given a Bayesian network model and a hypothesis variable, the task is to identify the variable, which is most informative with respect to the hypothesis variable.

\subsection{The BBN model}

Let $X$ be a discrete random variable taking the values $\left\{x_{1}, \ldots, x_{n}\right\}$ representing our current knowledge. However, this knowledge is not enough to determine which particular alternative that will materialise and therefore this knowledge shall be associated with our current uncertainty. This measure of uncertainty is determined by the number of available alternatives and the probability distribution $P(\cdot)$. A measure of our current uncertainty is also a measure of the amount of information that will be acquired when we determine the particular alternative.

If we assume that the measure of uncertainty be given by the logarithmic measure of the number of alternatives then it can be shown [8] that the average uncertainty associated with the random variable $X$ is given by

$$
H(X)=-\sum_{i=1}^{n} P\left(x_{i}\right) \log P\left(x_{i}\right), \text { where }
$$

$H$ is a Gibbs-Shannon entropy of the random variable $X$. Using logarithms to base 2, the unit of entropy is a bit. If we know that $X$ will assume the value $x_{1}$, then $P\left(x_{1}\right)=1$ and it follows that $H(X)=0$. If our current state of knowledge is total ignorance then we will not be able to distinguish between various alternatives and this leads to the uniform probability distribution $P\left(x_{1}\right)=1 / n$.

\section{BS RAC as a boundary organization}

The challenges for the Baltic fisheries management involve linking science and decision-making across different levels of the management system. First of all 
the ICES science based advice published in autumn is considered by the Scientific, Technical and Economic Committee on Fisheries (STECF), a committee of experts from the Member States which advises the European Commission. The Baltic Sea Regional Advisory Council is consulted by the European Commission and gives its opinion on the TACs and how the fisheries should be managed. Meanwhile, the European Commission conducts external negotiations on behalf of the Member States with Russia. After that the European Commission publishes its proposals for fishing quotas for the following year and at their December meeting the Council of Ministers negotiate and decide on TACs and quotas.

The boundary work of the BS RAC in balancing of stakeholder's interests in transformation of science-based advice into agreed management recommendations is considered to be an important element in setting the Baltic Sea TACs. Intended role of the BS RAC is to serve as negotiator between international scientific community - ICES and users (EU Commission) of scientific and technical advice and being accountable to both sides of the boundary. BS RAC acts as facilitator of dialogue between fishing industry, scientists and decision makers to encourage research agendas that reflect the interests and needs of fishery industry. BS RAC acts also as translator of scientific information produced by ICES, putting general findings into fisheryspecific practical language.

BS RAC is performing several essential hybrid management functions. One of them - hybridisation is performed by facilitating communication among scientists, fishing industry, non-governmental organizations, and political officials, engaged in formal and informal efforts to clarify both technical requirements and value choices, and helping negotiate compromise settlements among stakeholders. Another important hybrid management function deconstruction is performed by BS RAC basically with aim to reveal previously tacit assumptions and values laden in science based fisheries advice. The interpretation of the data and what it means for specified endpoints is seen as a technical judgment that usually is made by scientists. Deciding what to do about the technical judgment (e.g. science based opinion/advice) is considered to be a value judgment, reflecting the value-based weights assigned to different stakeholder objectives and, in the larger scheme, reflecting value weights assigned to Baltic ecosystem concerns as a part of overall Baltic fisheries management objectives. Hybrid management function - cross-domain co-ordination performed by BS RAC has taken a variety of forms, including, e.g. negotiation with EU Commission on planning and funding additional fishery science, and the provision of a forum for collective interpretation/evaluation of science based advice, and the related management decisions.

\subsection{Production of BS RAC advice as a hybridization process}

Production of BS RAC advice to the European Commission is involving extensive mixing of biological (fishery resources), socio-economic and public elements in balancing the interests of fisheries' associations, producer organisations, processors, market organisations, environmental NGOs, 
aquaculture producers, consumers, women's networks and recreational and sports fishermen.

\subsubsection{ICES science based advice}

ICES is providing advice on a range of issues relating to marine policies and management for the governments of ICES member countries, the European Commission and international intergovernmental organizations dealing with marine affairs such as the Helsinki Commission (HELCOM), the North Atlantic Salmon Commission (NASCO), the North East Atlantic Fisheries Commission (NEAFC) and the OSPAR Commission (OSPAR). ICES advice is based on the precautionary approach. Incremental implementation of ecosystem approach to management is including the stakeholder interaction.

The ICES advisory process could be seen as an example of efficient coproduction of science and policy. The concept of co-production well presented in the collection of essays by some of the leading scholars in the field [9] is explaining how scientific knowledge both embeds and is embedded in social identities, institutions, representations and discourses. Co-production of science and policy is considered to be an important element in production of usable science [10]. Usable science refers to the degree that the science produced through co-production process results in knowledge that meets constituent needs. Thus, the knowledge produced should directly reflect expressed constituent needs, should be understandable to users, should be available at the times and places it is needed, and should be accessible through the media available to the user community.

\subsection{Industry stakeholder's argumentation}

The BS RAC consultation process is influenced by the goals of its members. Stakeholders will have arguments that are presented as objective justifications, e.g. stakeholder believes that the status of the fishery resource justifies goal. Subjective justification of a goal is related to an internal evaluation that the stakeholder believes that the goal is achievable [5]. The fundamental role of the ICES science based advice on the status of exploited fish stocks is as information for the objective justification of the stakeholder's beliefs.

Current advisory systems in fisheries focus on the biological sciences and little quantitative advice is available about the social and economic impact of alternative management strategies, despite the development of a thorough theoretical grounding for assessing the economics of natural resource management and the strong need for managers to be informed about the social and economic consequences of their actions [11]. The principal reason why no such advice is provided is that the systematic collection of economic fisheries data on a Community basis by Member States to support production of such an advice started in 2004 only but also because there may not be a relevant economic target at the Community level. Consequently, the socio-economic arguments used by the BS RAC industry stakeholders sometimes cannot be clearly formulated and sufficiently justified. 


\subsection{Non-industry stakeholder's argumentation}

Argumentation of the BS RAC non-industry stakeholders, e.g. Fisheries Secretariat, WWF and Coalition Clean Baltic -, is usually based on the science based advice provided by the ICES. An important issue for that argumentation is the more firm acceptance of transparency about the uncertainty inherent in stock assessments while not using the uncertainty as an excuse for political compromise. According to Mace [12] "Attacks on the quality or validity of scientific stock assessments are becoming commonplace but, with few exceptions, the quality of the science is usually an inappropriate scapegoat.... The fact is that stock assessments will probably always be imprecise, but the appropriate response to imprecise assessments is to manage conservatively". At the same time the argumentation of the non-industry stakeholder's is usually not strong enough because insufficient knowledge on the fishing industry itself (fishing fleet, fishing effort, fishing capacity and fleet productivity, fuel and fish prices etc.), and again the argumentation is mainly focused on the dynamics of the fishery resources.

\subsection{BS RAC consultation process: balancing the stakeholder's interests}

The simple BBN model is used to conceptualize the BS RAC consultation process (Figure 1). This BBN network contains three information variables: 1) "Harvest Status" (sustainable/not sustainable), 2) "Public Argumentation" (reasoning in support of sustainable fishing - strong/weak), and 3) "Industry Argumentation" (industry's demand for the fish resources expressed by the BS RAC fishing industry representatives - strong/weak) and one hypothesis variable - "TAC Recommendation" (BS RAC recommendations to the European Commission on setting the TACs for internationally regulated Baltic fish stocks). This variable is representing the two options of the TACs recommendation (recommended TAC is less than or equal to the science based advice or recommended TAC is higher than science based advice). There are no direct connections presented between information variables and this captures our understanding that the influence of the status of these variables on the hypothesis variable - recommendations in relation to setting the TACs is mediated by different conditions.

The Bayesian network presented in Figure 1 is used as a casual network with both diverging and the converging connections. For example, if we know that as the result of the consultations the status of TACs recommendation given by the BS RAC is equal to " $>S C I A D V I C E$ " then, using diverging connections we can easily see which of the information variables have had the highest influence on recommendation status. In this case it is the strong "Industry Argumentation".

Value of information analysis in Bayesian network contain the computing the value of the initial information scenario $(H)$, and the value of information scenarios where a certain information variable $X$ is observed, i.e. $(H \mid X)$. The main reason for acquiring additional information is to decrease the uncertainty about the hypothesis under consideration. In our case (Figure 2) the most 


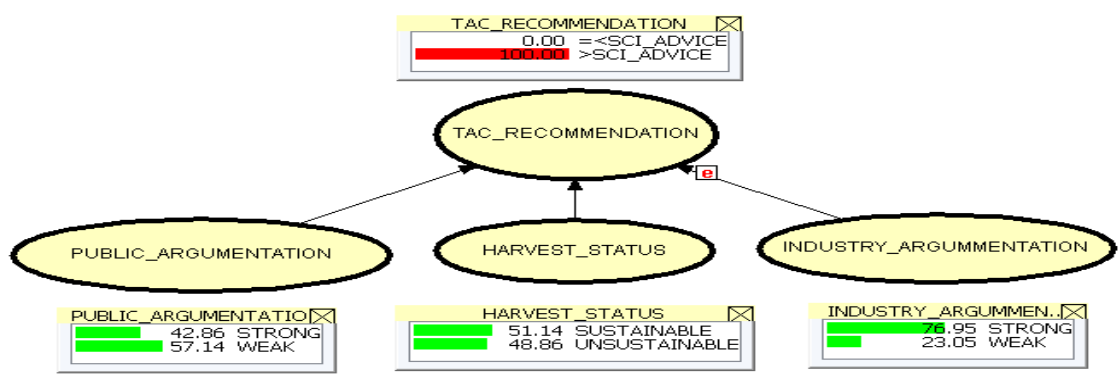

Figure 1: $\quad \mathrm{BBN}$ with hypothesis variable "TAC Recommendation" in a state equal "> SCI_ADVICE".

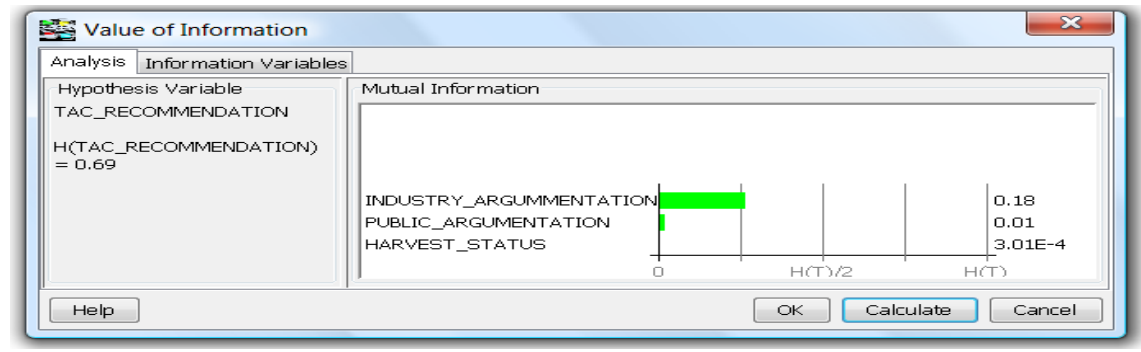

Figure 2: The mutual information between the hypothesis node and each of the selected information variables - one bar for each information variable.

informative variable to observe (Industry Argumentation) is the variable with the highest mutual information with the hypothesis variable (TAC Recommendation).

In the figure 2 the name of the information variable and the mutual information between the hypothesis node and the information variable are associated with each bar while the size of the bar is proportional to the ratio between the mutual information and the entropy of the hypothesis node.

Furthermore, if we would like to predict the most probable outcome of the BS RAC negotiations and we know, for example, that the state of the information variables is as follows: "Public Argumentation" equals "Strong", "Harvest Status" equals "Unsustainable", and the "Industry Argumentation" equals "Weak" then we can easily predict the outcome using the converging connections of the BBN (Figure 3).

As a result we can expect that the hypothesis variable "TAC Recommendation" will be in state equal " $<=$ Sci_Advice". It means that the BS RAC will recommend the exploitation of fish stock concerned on a level of exploitation believed to be sustainable. However, if the industry reasoning is expected to be strong given the status of the rest of variables remaining unchanged then there is a quite high probability that the BS RAC will recommend, referring to the industry's high demand for the fishery resource, to set the TAC for that particular fish stock at a level higher that is believed to be sustainable (Figure 4). 


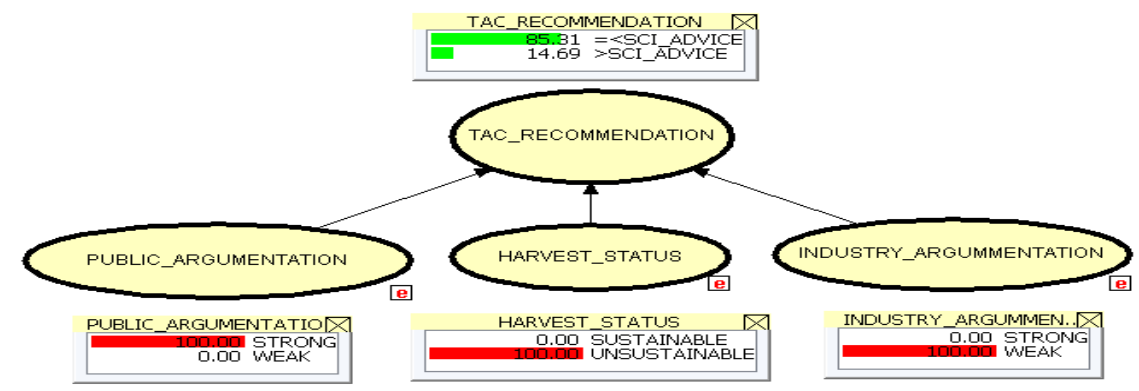

Figure 3: $\mathrm{BBN}$ with information variable "Industry Argumentation" in a state equal "Weak".

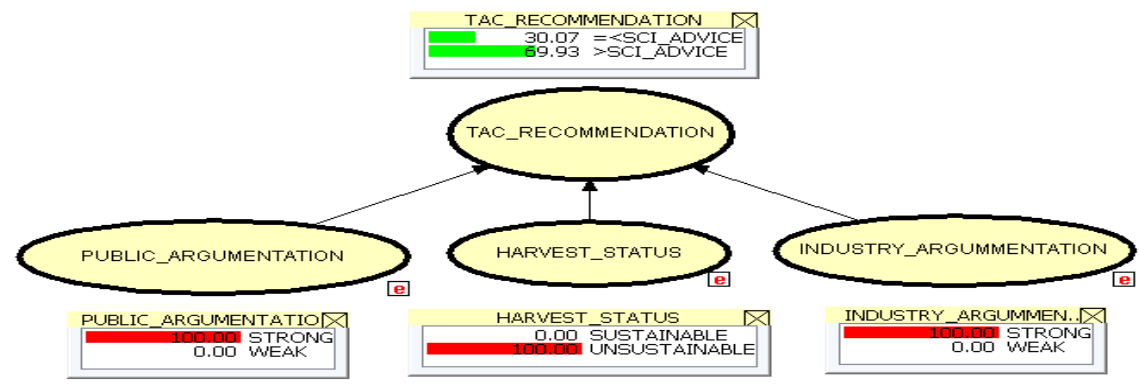

Figure 4: $\mathrm{BBN}$ with information variable "Industry Argumentation" in a state equal "Strong".

\section{The way forward}

The BS RAC is entering a period of difficult change during which it has to adjust its activities to meet the new challenges such as 1) developing the recommendations based on the concepts of Maximum Sustainable Yield (MSY) and the Maximum Economic Yield (MEY), and 2) defining the Baltic fisheries as a spatial resource with aim to secure the fishing industry's interests in the context of the coming age of Maritime Spatial Planning.

A target set out in the World Summit on Sustainable Development Plan of Implementation (WSSD PoI) is the restoration of fish stocks to sustainable levels that can produce the Maximum Sustainable Yield (MSY). It is foreseen that the main implementation tool will be the long term plans that will define the rate of fishing which can be exerted for each stock within the fishery concerned. The process of development of the long term plans will involve 1) production the best scientific advice available with due consideration of social and economic implications, and 2) the consultation of stakeholders, in particular the RACs, so that those most directly affected by the management decisions will have a chance to have their say. Correspondingly, the BS RAC should further develop the MSY related knowledge base and argumentation to be able to contribute efficiently to the development of the long term management plans. 
The BS RAC should also further develop the knowledge base and argumentation setting on the Maximum Economic Yield (MEY) that is usually defined as the optimal difference between fishing costs and profits. According to the World Bank and the UN Food and Agriculture Organization's Report [13] economists traditionally measure the net economic benefits from a natural resource such as a fish stock by economic rents. The economic objective is to maximize the net economic benefits (sustainable rents) flowing from the fishery while efficiency of fisheries may be measured as the difference between maximum rents obtainable from the fisheries and the actual rents currently obtained. Rent dissipation will be used as an efficient (inverse) metric both of the economic and biological health of the Baltic fishery.

Finally, the coming age of Maritime Spatial Planning will bring the fishing industry at the negotiation table with the representatives of other sea use interests (maritime transport, wind farms, mineral and oil extraction etc.) with aim to negotiate the allocation of the marine space concerned. And again, in order to meet the challenge the BS RAC should develop the sufficient knowledge base and argumentation setting to be efficient partner in a fully comprehensive, integrated, plan led system of management for the present and future exploitation and development of marine resources.

\section{Acknowledgements}

The manuscript was prepared with funding provided by the European Commission Research Directorates through the EU FP7 project JAKFISH "Judgement and Knowledge in Fisheries including Stakeholders".

\section{References}

[1] Miller, C. Hybrid management: boundary organizations, science policy, and environmental governance in the climate regime. Science, Technology \& Human Values, 26(4), pp. 478-500, 2001.

[2] Guston, D.H. Boundary organizations in environmental policy and science: an introduction. Science, Technology \& Human Values, 26(4), pp. 399-408, 2001.

[3] Anon. Sustainable use and management of natural resources. European Environmental Agency Report, 9, 72 p., 2005.

[4] Eagle, J., Thompson B. H. Answering Lord Perry's Question: Dissecting Regulatory Overfishing. Ocean and Coastal Management 46, pp. 649-679, 2003.

[5] Aps, R. Negotiated Decisions on Baltic Fishery Resource Allocation. US/EU-Baltic Symposium "Ocean Observations, Ecosystem-Based Management \& Forecasting”; Tallinn; 27-29 May, 2008. IEEE-Inst Electrical Electronics Engineers Inc, IEEE Xplore, pp. 204-208, 2008.

[6] Baltic Sea RAC. Statements and recommendations: http://www.bsrac.org/ ooizzCMS/DA/statementsandrecommendations. 
[7] International Council for the Exploration of the Sea. Advice: Baltic Sea. http://www.ices.dk/advice/icesadvice.asp.

[8] Caves, C.M., Fuchs, C.A. Quantum Information: How much Information in a State Vector, quant-ph/9601025, http://xxx.lanl.gov/archive/quant-ph., 1996.

[9] Jasanoff, S. States of Knowledge: The Co-production of Science and Social Order. Published by Routledge: 317 p., 2004.

[10] Lemos, M.C., Morehouse B.J. The co-production of science and policy in climate assessments. Global Environ. Change, 15(1), 57-68.

[11] Anon. Communication from the Commission (2003/C 47/06) on improving scientific and technical advice for Community fisheries management. http://eur-lex.europa.eu/LexUriServ/ LexUriServ.do?uri=OJ:C:2003:047: 0005:0016:EN:PDF, 2003.

[12] Mace, P. Developing and sustaining world fisheries resources: the state of the science and management. In: Developing and Sustaining World Fisheries Resources: the State of the Science and Management, Proceedings of the Second World Fisheries Congress (Ed. by D. A. Hancock, D. C. Smith, A. Grant and J. P. Beumer), CSIRO Publishing, Collingwood, Australia, pp. 1-20, 1997.

[13] Anon. The Sunken Billions. The Economic Justification for Fisheries Reform. World Bank and Food and Agriculture Organization, Agriculture and Rural Development Department. The World Bank. Washington DC. 86 p., 2008. 